\title{
A new species of Hyperimerus Girault from China, with a key to species of the genus (Hymenoptera, Chalcidoidea, Pteromalidae)
}

\author{
Lan Yang',2, Da-wei Huang ${ }^{2}$, Hui Xiao'
}

I Key Laboratory of Zoological Systematics and Evolution, Institute of Zoology, Chinese Academy of Sciences, Beijing, 100101, China 2 College of Life Science and Technology, Hebei University, Baoding, 071002, China

Corresponding author: Hui Xiao (xiaoh@ioz.ac.cn)

Academic editor:A. Köhler | Received 19 September 2018 | Accepted 26 November 2018 | Published 15 January 2019

http://zoobank.org/75E77E80-44D2-4BAD-B987-0248726B4EB3

Citation: Yang L, Huang D-w, Xiao H (2019) A new species of Hyperimerus Girault from China, with a key to species of the genus (Hymenoptera, Chalcidoidea, Pteromalidae). ZooKeys 817: 105-112. https://doi.org/10.3897/ zookeys.817.29886

\begin{abstract}
A new species of Hyperimerus Girault (Hymenoptera: Pteromalidae), H. sichuanicus Yang \& Xiao, sp. n., is reported and described for the first time from mainland China. A key to the worldwide species of $H y$ perimerus and illustrations of external features of the species are also provided.
\end{abstract}

\section{Keywords}

China mainland, key, Hyperimerus, new species, Pteromalidae, taxonomy

\section{Introduction}

The genus Hyperimerus was erected by Girault (1917) to include Hyperimerus corvus Girault from California, USA, and the genus was placed in the subfamily Erimerinae of Callimomidae. Subsequently, Hyperimerus was put in the tribe Asaphini under Pteromalidae by Peck (1951). Graham (1969) upgraded the tribe Asaphini to subfamily Asaphinae. Since then, several researchers reported Hyperimerus from Europe (Graham 1969; Bouček 1977; Dzhanokmen 1978; Kalina 1989; Ulrich 1999). Schender et al. (2014) reviewed the genus and redescribed the two species, $H$. corvus Girault and $H$. pusillus (Walker). Until now, two valid species of Hyperimerus are known in the world.

Copyright Lan Yang et al. This is an open access article distributed under the terms of the Creative Commons Attribution License (CC BY 4.0), which permits unrestricted use, distribution, and reproduction in any medium, provided the original author and source are credited. 
Only one species, $H$. pusillus (Walker), has previously been reported in China (Huang and Xiao 2005). In this study, one new species, H. sichuanicus Yang \& Xiao, sp. n., is described.

\section{Materials and methods}

All specimens for the present study were swept using an insect net and preserved in 95\% ethanol. They were subsequently air dried, point-mounted and examined with a LEICA MZ APO stereomicroscope. Photographs were taken under the Nikon Multizoom AZ100 system, and the plates were compiled using Adobe Photoshop software. In addition, the author also examined the specimens of Hyperimerus deposited in the National History Museum, London in 2002. All type specimens of the new species are deposited in the Institute of Zoology, Chinese Academy of Sciences, China (IZCAS).

Morphological terminology mostly follows that of Bouček (1988) and Gibson et al. (1997). All specimens were examined and identified based on the studies of Graham (1969), Gibson and Vikberg (1998), Bouček and Rasplus (1991) and Schender et al. (2014). The new species is described based on the holotype specimen. Body length excluding the ovipositor sheaths is measured in millimetres $(\mathrm{mm})$; other measurements are given as ratios. Abbreviations of morphological terms used are:

Fu funicular segment number;

POL posterior ocellar distance;

OOL ocellocular distance;

$\mathbf{G t}_{\mathbf{n}}$ gastral tergum number.

\section{Taxonomy}

\section{Key to species}

$1 \quad \mathrm{Fu}_{1}$ shorter than pedicel; ovipositor sheaths shortly protruded, shorter than $1 / 2$ length of gaster

- $\quad \mathrm{Fu}_{1}$ longer than pedicel; ovipositor sheaths distinctly protruded, ca. 2/3 length of gaster H. corvus Girault

2 Clava as long as $\mathrm{Fu}_{5}-\mathrm{Fu}_{7}$ combined; marginal fringe of outer margin of fore wing longer than length of uncus; propodeum with irregularly and densely areolate sculptures (Fig. 5), most cells of sculpture as big as propodeal spiracles

H. sichuanicus sp. $\mathrm{n}$.

- $\quad$ Clava shorter than length of $\mathrm{Fu}_{5}-\mathrm{Fu}_{7}$ combined; marginal fringe of outer margin of fore wing shorter than length of uncus; propodeum with irregularly and sparsely sculptures (Fig. 10), most cells of sculpture more than $2 \times$ as big as propodeal spiracles. 


\section{Hyperimerus Girault, 1917}

Hyperimerus Girault, 1917: 5. Type species: Hyperimerus corvus Girault, by original designation.

Hyperimerus Girault: Graham 1969: 83-84; Huang and Xiao 2005: 281-282; Schender et al. 2014: 408-420.

Mespilon Graham, 1957: 406. Type species: Mespilon exiguum Graham, by original designation. Synonymized by Bouček 1965: 549.

Diagnosis. Body with dense hairy, head and mesosoma with engraved reticulate sculpture. Head subtriangular in frontal view; antennal scrobes deep, not reaching anterior ocellus; malar sulci distinct; antennal insertion obviously below centre of face; formula 11173. Head in dorsal view, occiput with horseshoe-like carina. Pronotum quadrangular; notauli complete, frenal line on scutellum indistinct; propodeal sculptures irregular; fore wing with pilosity, speculum absent; postmarginal vein longer than marginal vein. Gaster convex, petiole transverse, $\mathrm{Gt}_{1}$ and $\mathrm{Gt}_{2}$ large and smooth, ovipositor sheath exerted.

Hyperimerus is similar to Asaphes in the subfamily Asaphinae, but it can be recognized by the antenna with one anellus and seven funicular segments (two anelli and six funicular segments in Asaphes), frenal line on scutellum indistinct (distinct in Asaphes), petiole transverse (petiole longer than broad and with longitudinal ridges in Asaphes).

Biology. Hyperimerus is recorded as parasites of Pseudococcus (Hemiptera: Pseudococcidae), Psylla (Hemiptera: Psyllidae), Lymantria (Lepidoptera: Erebidae), Choristoneura, Zeiraphera (Lepidoptera: Tortricidae), Chrysopa (Neurop: Chrysopidae), Hemerobius, and Sympherobius (Neuroptera: Hemerobiidae) (Graham 1969; Burks 1979; Schender et al. 2014; Noyes 2018). The genus is associated with the following plants: Fagus sylvatica, Pyrus communis (Dzhanokmen 1978; Ghahari et al, 2010).

Distribution. China (Sichuan, Tibet); Holarctic, Oriental, and Neotropical regions.

\section{Hyperimerus sichuanicus Yang \& Xiao, sp. n.}

http://zoobank.org/36329DB9-9E34-44E8-8CEB-D7773E07A6AA

Figs 1-6

Diagnosis. Antenna with $\mathrm{Fu}_{1}$ shorter than pedicel; $\mathrm{Fu}_{7}$ quadrate, clava as long as $\mathrm{Fu}_{5}-$ $\mathrm{Fu}_{7}$ combined; marginal fringe of outer margin of fore wing longer than length uncus; postmarginal vein $1.65 \times$ as long as stigmal vein; propodeum with irregularly and densely sculptured, most of them as big as propodeal spiracles; ovipositor sheaths protruded, not longer than $1 / 2$ length of gaster.

Description. Female (holotype). Body length $1.4 \mathrm{~mm}$. Head and body dark green with bluish reflection. Mandibles brown, antennae dark brown. Coxae concolorous with body, remainder of legs brown except tibiae yellowish brown, colour gradation from yellowish brown to brown at tarsi. 


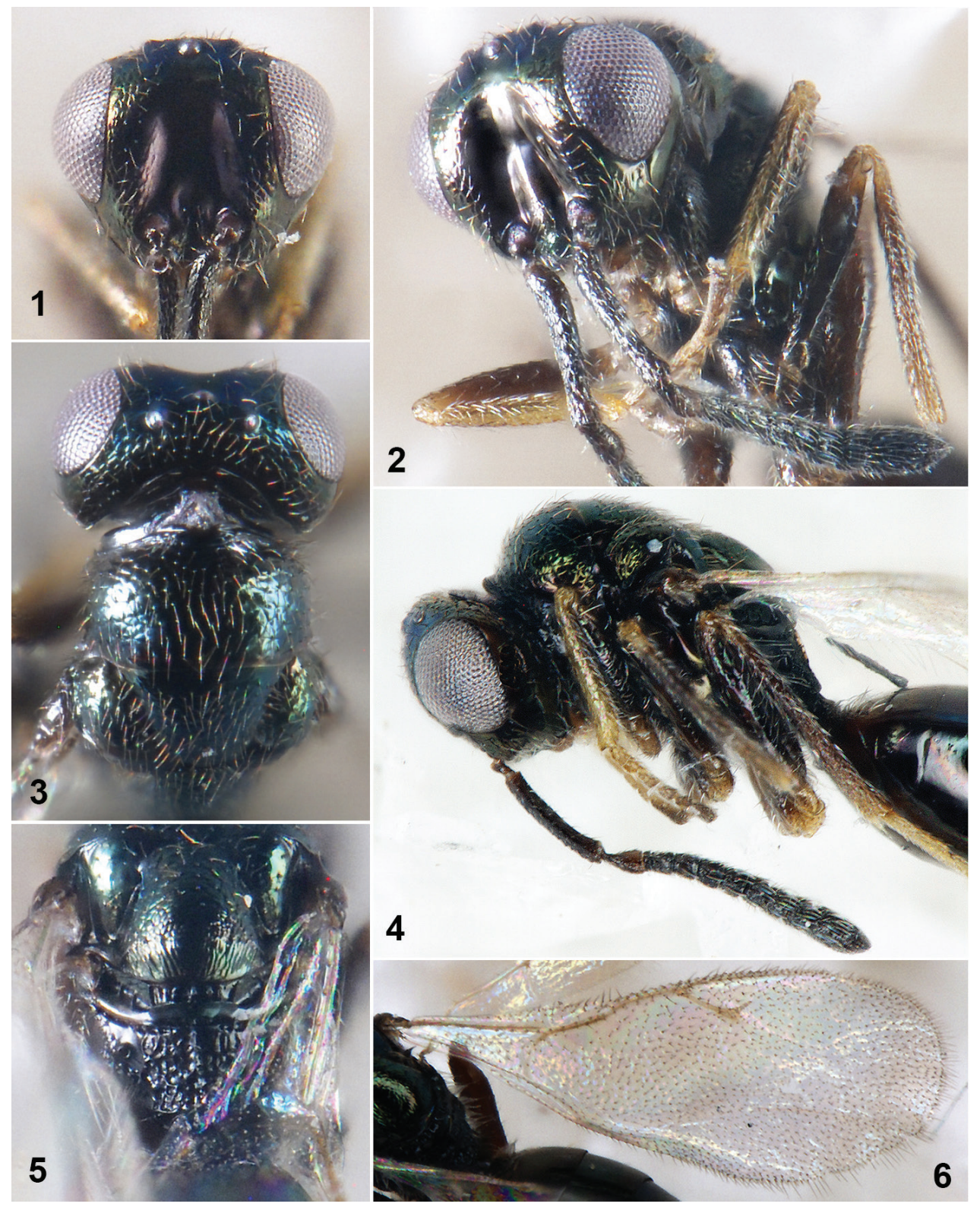

Figures I-6. Hyperimerus sichuanicus sp. n., female holotype I Head in frontal view $\mathbf{2}$ Head in lateral view 3 Head and pronotum in dorsal view 4 Antenna and thorax in lateral view 5 Propodeum in dorsal view 6 Fore wing in dorsal view.

Head in frontal view $1.26 \times$ as wide as high (Fig. 1); eyes height $0.62 \times$ head height; eyes separated by $1.24 \times$ their height. Antennal scrobes deep and glabrous, not reaching anterior ocellus (Fig. 2), interantennal crest distinct. Clypeal suture obvious, clypeus and supraclypeal area slightly prominent, clypeal margin truncate. Antennal insertion on lower ocular line, close to clypeal margin, distance from upper margin of torulus 
to lower margin of anterior ocellus $7 x$ distance from lower margin of torulus to lower margin of clypeus. Gena smooth and convex; malar sulci distinct, malar space $0.67 \times$ eyes height. Antenna (Fig. 4) clavate; scape $1.14 \times$ eyes height, reaching anterior ocellus; length of pedicel and flagellum combined longer than head width (1.16x); pedicel conical, $2 \times$ as long as broad in lateral view; anellus transverse; each funicular segment and clava segment with single row of sensilla; ratio of length and width from $\mathrm{Fu}_{1}$ to $\mathrm{Fu}_{7}$ as 3:3, 4:3.5, 4:4, 5:4, 5:4, 5:5, 5:5; clava equal to length of $\mathrm{Fu}_{5}-\mathrm{Fu}_{7}$ combined. Head in dorsal view, $1.95 \times$ as wide as long (Fig. 3); vertex convex, POL 2.75x OOL.

Head $1.27 \times$ as broad as mesosoma. Mesosoma convex, $1.76 \times$ as long as broad. Pronotum, mesoscutum and anterior area of scutellum with engraved reticulation. Pronotum $0.91 \times$ as broad as mesoscutum. Mesoscutum $2 \times$ as broad as long; notauli deep and complete. Scutellum weakly convex, frenal line obscured medially, frenum with longitudinal rugae (Fig. 5), frenum ca. 1/5 length of scutellum. Dorsellum glabrous, $4 \times$ as broad as long, $0.17 \times$ as long as propodeum. Propodeum (Fig. 5) $0.71 \times$ as long as scutellum, median carina distinct; areolate sculptures on median area irregular and dense, most cells as big as propodeal spiracles; area otherwise glabrous; propodeal spiracles ovate, separated from metanotum by $1.5 \times$ spiracular width; callus densely hairy laterally and posteriorly. Prepectus smooth and with sparse hairy. Upper mesepisternum setose and finely reticulate, area otherwise smooth. Fore wing (Fig. 6) $2.63 \times$ as long as broad, speculum absent; marginal fringe of outer margin of fore wing longer than length of uncus; costal cell with sparse setae; ratio of submarginal vein: marginal vein: postmarginal vein: stigmal vein as 49:18:26:16; stigmal vein oblique, stigma slightly expand, uncus ca. $1 / 4$ length of stigmal vein.

Gaster ovate, $1.88 \times$ as long as broad, shorter than head and mesosoma combined. Petiole short, $0.5 \times$ as long as broad, dorsum with longitudinal ridges. Each gastral tergite smooth; $\mathrm{Gt}_{1}$ with long hairy around petiole; $\mathrm{Gt}_{1}$ and $\mathrm{Gt}_{2}$ large and smooth, $0.47 \times$ length of gaster. Ovipositor sheaths distinctly produced in dorsal view; gaster in lateral view, ovipositor sheaths $0.47 \times$ length of gaster, $0.76 \times$ length of hind tibia.

Male. Body slender, scape yellowish-brown, antenna segmented clearly, others similar to the female.

Remarks. The new species is similar to $H$. corvus, but different by the antenna with $\mathrm{Fu}_{1}$ shorter than pedicel, ovipositor sheaths shortly protruded. It is also very close to $H$. pusillus in having the $\mathrm{Fu}_{1}$ shorter than pedicel, ovipositor sheaths shorter than $1 / 2$ length of gaster, but can be recognized by the characters listed in the key.

Material examined. Holotype. China, + , Sichuan: Kangding, $30.04^{\circ} \mathrm{N}$, 101.57 E, 15.VI.2017, leg. Yanzhou Zhang (Hyp-2018-06, original number ZYZ2017-28). Paratypes. $191 \hat{\jmath}$, Sichuan: Kangding, 29.VI.2017, leg. Yanzhou Zhang (Hyp-2018-01, Hyp-2018-02, original number ZYZ-2017-08); 1 , , Sichuan: Kangding, 2.VIII.2017, leg. Yanzhou Zhang (Hyp-2018-03, original number ZYZ-201720); 10 , Sichuan: Kangding, 29.VI.2017, leg. Yanzhou Zhang (Hyp-2018-08, original number ZYZ-2017-029).

Etymology. Named after the location of the type material.

Hosts. Unknown.

Distribution. China (Sichuan). 


\section{Hyperimerus pusillus (Walker, 1833)}

Figs 7-10

Cyrtogaster pusilla Walker, 1833: 383. Holotype female (BMNH No. 3300), examined. Hyperimerus pusillus (Walker): Graham 1969: 83; Bouček 1993: 1306; Huang and Xiao 2005: 281-282; Schender et al. 2014: 414-417.

Mespilon exiguum Graham, 1957: 406. Synonymized by Graham 1969: 83.

Diagnosis. Female. Body (Fig 7, 8) length approximately $1.5 \mathrm{~mm}$, dark green. Head width $1.32 \times$ height in frontal view. Eyes height $0.58 \times$ head height; eyes separated by $1.07 \times$ their height. Gena with malar sulci distinct, malar space $0.55 \times$ eyes height. Antenna (Fig. 9) with scape reaching anterior ocellus; pedicel and flagellum combined $1.2 \times$ head width; pedicel broader than $\mathrm{Fu}_{1}$, clava shorter than length of $\mathrm{Fu}_{5}-\mathrm{Fu}_{7}$ combined. Scutellum with frenum ca. 1/3 length of scutellum. Propodeum with areolate sculptures irregular and sparse, most of sculptures $2 \times$ as big as propodeal spiracles (Fig. 10). Marginal fringe of outer margin of fore wing shorter than length of uncus; marginal vein shorter than postmarginal vein $(0.59 \times)$, postmarginal vein approximately $1.85 \times$ as long as stigmal vein. Petiole $0.4 \times$ as long as broad. Gaster $1.91 \times$ as long as broad; narrower than thorax, shorter than the length of head and mesosoma

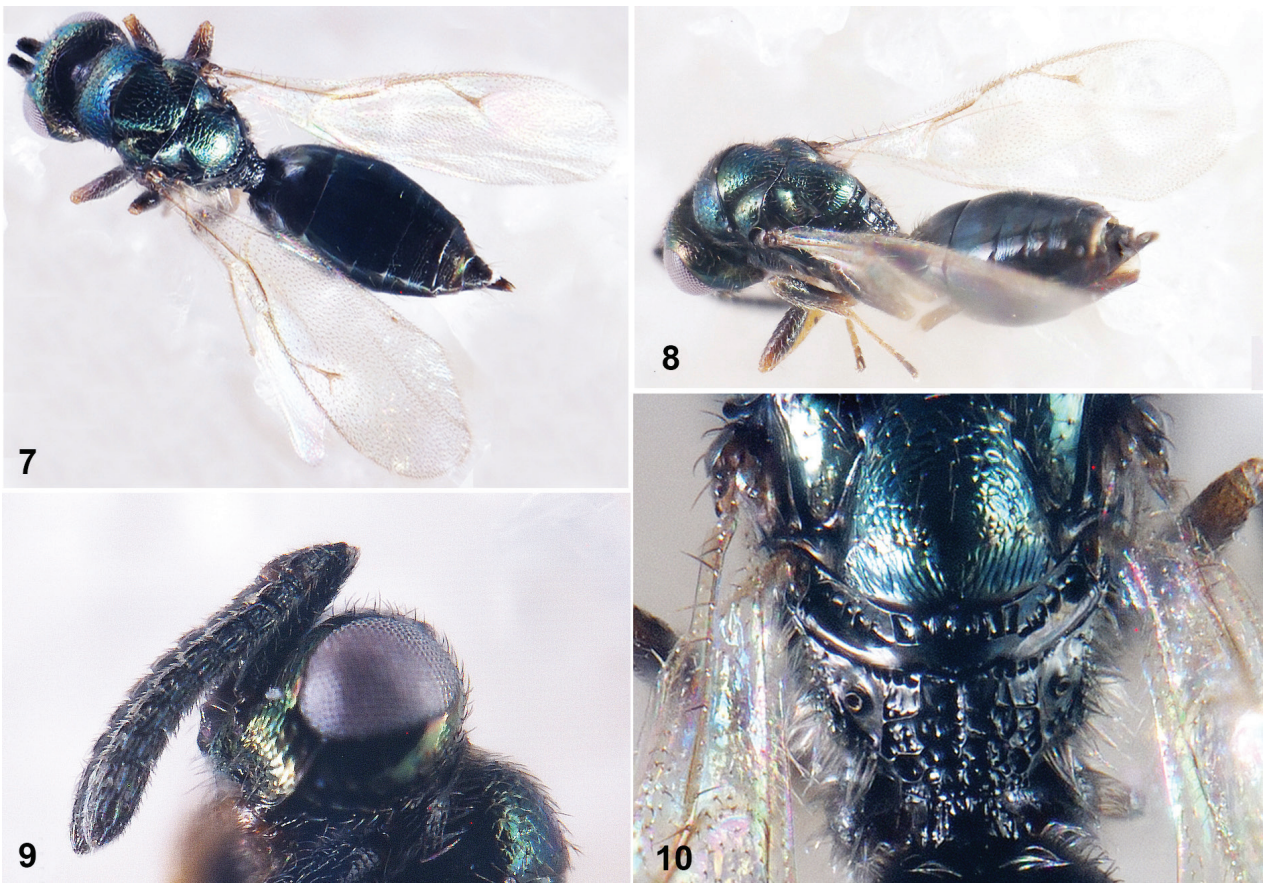

Figures 7-10. Hyperimerus pusillus (Walker, 1833) 7 Body in dorsal view 8 Body in lateral view 9 Head and antenna in lateral view 10 Propodeum in dorsal view. 
combined. Ovipositor sheaths slightly produced in dorsal view; gaster in lateral view, ovipositor sheaths $0.26 \times$ length of gaster, $0.44 \times$ length of hind tibia.

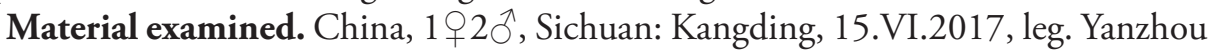
Zhang (Hyp-2018-07, original number ZYZ-2017-28; Hyp-2018-09, original number ZYZ-2017-29); 1 q , Sichuan: Kangding, 2.VIII. 2017, leg. Yanzhou Zhang (Hyp2018-04, original number ZYZ-2017-21); 1q, Sichuan: Kangding, 29.VI.2017, leg. Yanzhou Zhang (Hyp-2018-11, original number ZYZ-2017-42); 1§, Tibet: Zhamo, 2700m, VII. 19.1978, leg. Fasheng Li.

Hosts. Parasitoids of Psylla pyricola (Ghahari et al., 2010), Phenacoccus aceris, Psylla ulmi (Dzhanokmen, 1978).

Distribution. China (Sichuan, Tibet), Holarctic, Oriental, and Neotropical regions.

\section{Acknowledgements}

We thank Dr Xu Zhang, and Dr Yanzhou Zhang, Institute of Zoology of CAS, for supplementing specimens. This work was supported by the National Natural Science Foundation of China under Grant Number 31672328 and 31750002.

\section{References}

Bouček Z (1965) Synonymic and taxonomic notes on some Chalcidoidea (Hymenoptera), with corrections of my own mistakes. Sborník Entomologického Oddeleni Národního Musea v Praze 36: 543-554.

Bouček Z (1977) A faunistic review of the Yugoslavian Chalcidoidea (Parasitic Hymenoptera). Acta Entomologica Jugoslavica 13(Supplement): 1-145.

Bouček Z (1988) Australasian Chalcidoidea (Hymenoptera). A biosystematic revision of genera of fourteen families, with a reclassification of species. CAB International, Wallingford, Oxon, U.K., Cambrian News Ltd., Aberystwyth, Wales, 832 pp.

Bouček Z (1993) New taxa of North American Pteromalidae and Tetracampidae (Hymenoptera), with notes. Journal of Natural History 27: 1239-1313. https://doi. org/10.1080/00222939300770741

Bouček Z, Rasplus JY (1991) Illustrated key to West-Palaearctic genera of Pteromalidae (Hymenoptera: Chalcidoidea). Institut National de la Recherche Agronomique, Paris, 140 pp.

Burks BD (1979) Torymidae (Agaoninae) and all other families of Chalcidoidea (excluding Encyrtidae). Catalog of Hymenoptera in America North of Mexico 1: 768-889.

Dzhanokmen KA (1978) Hymenoptera III. Chalcidoidea 5. Pteromalidae. Opredeliteli Nasekomykh Evropeyskoy Chasti SSR 3: 57-228.

Gibson GAP, Huber JT, Woolley JB (1997) Morphology and Terminology. In: Gibson GAP, Huber JT, Woolley JB (Eds) Annotated Keys to the Genera of Nearctic Chalcidoidea (Hymenoptera). National Research Council Research Press, Ottawa, Canada, 794 pp. 
Gibson GAP, Vikberg V (1998) The species of Asaphes Walker from America north of Mexico, with remarks on extralimital distributions of taxa (Hymenoptera: Chalcidoidea, Pteromalidae). Journal of Hymenoptera Research 7(2): 209-256.

Girault AA (1917) Descriptions Hymenopterorum chalcidoidicarum variorum cum observationibus III. Private publication, Glenndale, $10 \mathrm{pp}$.

Ghahari H, Huang J, Ostovan H, Rastegar J (2010) Notes on the Iranian fauna of Pteromalidae (Hymenoptera). Efflatounia 10: 21-25.

Graham MWR de V (1957) A new genus and species of Pteromalidae (Hym., Chalcidoidea). Entomologist's Monthly Magazine 92: 406-408.

Graham MWR de V (1969) The Pteromalidae of North-Western E urope (Hymenoptera: Chalcidoidea). Bulletin of the British Museum (Natural History) (Entomology) 16: 1-908.

Huang DW, Xiao H (2005) Hymenoptera Pteromalidae. Fauna Sinica. Insecta, 42. Science Press, Beijing, 388 pp.

Kalina V (1989) Checklist of Czechoslovak Insects III (Hymenoptera). Chalcidoidea. Acta Faunistica Entomologica Musei Nationalis Pragae 19: 97-127.

Noyes JS (2018) Universal Chalcidoidea Database. http://www.nhm.ac.uk/chalcidoids [Accessed 21 July 2018]

Peck O (1951) Superfamily Chalcidoidea. In: Muesebeck CFW, Krombein KV, Townes HK (Eds) Hymenoptera of America north of Mexico - synoptic catalog.. Agriculture Monographs. U.S. Department of Agriculture 2: 410-594.

Schender D, Katz K, Gates MW (2014) Review of Hyperimerus (Pteromalidae: Asaphinae) in North America, with redescription of Hyperimerus corvus (Girault). Proceedings of the Entomological Society of Washington 116(4): 408-420. https://doi.org/10.4289/00138797.116.4.408

Ulrich W (1999) Phenology, stratification and life cycles of the parasitic Hymenoptera in a beech forest on limestone. Polskie Pismo Entomologiczne 68(3): 231-257.

Walker F (1833) Monographia Chalciditum. EntomologicalMagazine 1(4): 367-384. 